\title{
MULTIPLE ANAESTHETICS IN A PATIENT WITH PHAEOCHROMOCYTOMA
}

\author{
Gerald Edelist
}

IN THE PAST, the mortality from surgery in patients with undiagnosed phaeochromocytoma has been exceedingly high. ${ }^{1}$ However, once the condition has been diagnosed, modern drug therapy including the use of alpha and beta adrenergic blockers has somewhat simplified the management of these cases. ${ }^{2}$ We are reporting this patient's case as an example of both situations, as he had one anaesthetic while his phaeochromocytoma was undiagnosed, one anaesthetic during which the phaeochromocytoma was diagnosed and two anaesthetics with the diagnosis of phaeochromocytoma confirmed biochemically.

\section{Case Report}

This 58-year-old male was admitted with a history of bowel obstruction and was scheduled for an emergency transverse colostomy. His past history was unremarkable except for a history of labile hypertension which was untreated. He was anaesthetized with a thiopentone induction after premedication with meperidine $75 \mathrm{mgm}$ and atropine $0.4 \mathrm{mgm}$ intramuscularly. The trachea was intubated after paralysis with succinylcholine using the "crash intubation" technique. Anaesthesia was maintained with nitrous oxide, oxygen and halothane using pancuronium for muscle relaxation.

During the procedure the patient's blood pressure was steadily recorded at 230/130 with no cardiac arrhythmia noted, although the electrocardiogram was not monitored. The diagnosis of carcinoma of the sigmoid colon was made and after an uneventful recovery the patient was re-scheduled for colon resection. $\mathrm{He}$ was premedicated with diazepam $10 \mathrm{mgm}$ and induced with thiopentone. Pancuronium $6 \mathrm{mgm}$ was given for intubation and there was an immediate rise in blood pressure to $260 / 130$. This increased after preparation of the abdomen to over 300 torr systolic. At this point we were consulted as to the further management of the patient. Since we felt phaeochromocytoma was a distinct possibility we tested this hypothesis by starting 1 per cent halothane which after several minutes did not decrease the blood pressure and instead caused some ventricular premature contractions. Anaesthesia was discontinued and the patient awakened with his blood pressure returning to $140 / 90$ in the recovery room. During the next two weeks the patient had a medical workup for phaeochromocytoma with the diagnosis being

Correspondence to G. Edelist, M.D., Department of Anaesthesia, Mount Sinai Hospital, 600 University Avenue, Toronto, Ont. M5G 1X5.

Department of Anaesthesia, Mount Sinai Hospital, and University of Toronto. 
confirmed by a urinary V.M.A. of $17.4 \mathrm{mcg} / \mathrm{mg}$ of creatinine in 24 hours (normal $6.8 \mathrm{mcg}$ ) and urinary catecholamine level of $290 \mathrm{mcg}$ in 24 hours (normal $100 \mathrm{mcg}$ ).

Selected angiography suggested that the tumor might be in the right adrenal gland. Once this diagnosis was made the surgical plan was first to remove the carcinoma of the sigmoid and at the same time explore the abdomen to ensure that the phaeochromocytoma was in fact in the right adrenal gland. Pretreatment with phenoxybenzamine was discussed, but since the patient had begun to bleed from his tumour we felt that sudden bleeding in the face of alpha blockade was undesirable. Moreover, the pre-operative blood volume study showed total blood volume of $6.8 \mathrm{~L}$ with plasma volume of $4.3 \mathrm{~L}$. The fact that these were not low suggested that the only reason for alpha blockade was to prevent hypertension during operation and we felt that this could be accomplished by acute blockade by phentolamine.

This time the patient was premedicated with meperidine $75 \mathrm{mgm}$, promethazine $25 \mathrm{mgm}$ and atropine $0.4 \mathrm{mgm}$. Anaesthesia was induced with $7 \mathrm{cc}$ of Innovar ${ }^{\circledR}$ and nitrous oxide and oxygen. Pancuronium $8 \mathrm{mgm}$ was used to produce relaxation for intubation. The trachea was sprayed with 4 per cent lidocaine and tracheal intubation was accomplished. His blood pressure by direct measurement rose from 160/90 to $240 / 120$. Central venous pressure also rose from 7 to $12 \mathrm{~cm} \mathrm{H}_{2} \mathrm{O}$. At this point his pulse rate was 160 with occasional premature ventricular contractions. A phentolamine drip was initiated which controlled his blood pressure to $150 / 90$ and then propronalol $1 \mathrm{mgm}$ was administered. Pulse rate decreased to a regular sinus rhythm of 90 per minute. For the remainder of the bowel resection the vital signs remained stable. The position of the colostomy obviated exploration of the right adrenal but the remainder of the abdomen was explored and no phaeochromocytoma was discovered. This, together with the suggestion on angiography, confirmed the right adrenal as the most likely source. At the termination of the operation the paralysis was not reversed but the patient was artificially ventilated until the following morning and made an uneventful recovery. We did not wish to give atropine and neostigmine to a patient who, by virtue of his phaeochromocytoma, was already prone to cardiac arrhythmia. Eight weeks later he returned once more for excision of his phaeochromocytoma and closure of colostomy.

Owing to the rather marked elevation of blood pressure during his previous operation and the thought that if the patient had an alpha adrenergic blockade that beta blockade for the tachycardia would be safer, he was prepared with phenoxybenzamine $10 \mathrm{mgm}$ t.i.d. for ten days. He was again prepared with indwelling arterial line, C.V.P. line, E.C.G., urinary catheter, and premedicated with meperidine $75 \mathrm{mgm}$, promethazine $25 \mathrm{mgm}$ and atropine $0.4 \mathrm{mgm}$. He was induced with Innovar $7 \mathrm{cc}$, intubated with the aid of $8 \mathrm{mgm}$ of pancuronium and maintained with nitrous oxide and oxygen. His blood pressure rose to a maximum of 200/100 once during the operation. No beta blockers were necessary and no arrhythmias developed.

When the tumour was removed the blood pressure gradually fell to 120/90 and has remained at that level since. At the termination of the operation the muscle relaxation was reversed with neostigmine $2.5 \mathrm{mgm}$ and atropine $1.2 \mathrm{mgm}$ and recovery was uneventful. 
This case report illustrates some of the problems that can be encountered during anaesthesia for phaeochromocytoma. These include extreme hypertension. tachycardia and cardiac arrythmias which, if untreated, could lead to cardiac failure, cardiac arrest, cerebrovascular accident and renal failure in the post-operative period. The hypertension due to release of norepinephrine from the tumour can be initiated by palpation of the tumour, and by any factor that might normally precipitate an increase in catecholamines such as hypoxia, hypercarbia, acidosis, light anaesthesia, the histamine release which may be caused by drugs used during anaesthesia and particularly by curare. The arrhythmias are due to the beta effect of epinephrine release particularly when agents incompatible with epinephrine, such as halothane, are used. We did not encounter the problem of severe hypotension after tumour removal because this man's pre-operative blood volume was always normal and during operation fluids and blood were given to keep his central venous pressure normal. The cause of hypotension after tumour removal has been ascribed to release of vasoconstriction in a patient with a contracted blood volume in response to this vasoconstriction. In light of this case report we suggest the following principles should be followed in the anaesthetic management of phaeochromocytoma:

1. High index of suspicion in anyone who develops unusual hypertension or tachycardia during anaesthesia not responsive to the usual methods of treatment.

2. Preoperative blood volume study with replacement of plasma volume if this is low.

3. Preoperative alpha blockade with phenoxybenzamine to release vasoconstriction, allow plasma expansion and prevent marked systolic hypertension.

4. If preoperative blockade is not possible, intra-operative alpha blockade with phentolamine.

5. Pre-medication with an antihistamine to counteract the effects of drugs which may release histamine.

6. Monitoring of direct arterial pressure, central venous pressure or pulmonary capillary wedge pressure if possible, electrocardiogram and urinary output.

7. Use of anaesthetic agents compatible with epinephrine release. Innovar $\left.{ }^{(}\right)$and nitrous oxide seem good choices. We would avoid drugs known to release histamine such as curare and those incompatible with epinephrine, such as halothane.

8. We would reserve beta blockade for the operative period since it can be rapidly established with intravenous propranalol and allows one to avoid the problems of chronic beta blockade such as poor myocardial response to haemorrhage and hypoxia. It should be remembered that beta blockade should not be initiated in the face of hypertension caused by severe peripheral vasoconstriction, because this will lead to cardiac failure. Therefore, afterload should be decreased by alpha blockade before beta blockade is undertaken.

\section{SUMMARY}

A patient with phaeochromocytoma was anaesthetized on four separate oc- 
casions. Some of the problems associated with this disease are discussed and recommendations for anaesthetic management are made.

\section{RÉSUMÉ}

Un patient porteur d'un phéochromocytome a été anesthésie à quatre reprises. Quelques uns des problèmes liés à cette maladie sont discutés dans ce travail. Des recommandations pour la conduites de l'anesthésie sont faites.

\section{REFERENCES}

1. VAN Way, C.S. III, Scott, H.W., JR., PAGe, D.C., \& Rhoncy, R.K. Phaeochromocytoma. Curr. Publ. Surg. 1-59 (June 1974).

2. Hahrison, T.S., Bartlett, J.D., Jr., \& Seaton, J.F. Current evaluation and management of phaeochromocytoma. Ana. Surg. 168: 701 (1968). 